\title{
Patient access to compounded drugs in paediatrics after discharge from a tertiary centre
}

\author{
Marie-Kim Héraut PharmD MSc ${ }^{1}$, Minh-Thu Duong PharmD MSc ${ }^{1}$, \\ Clara Elchebly PharmD MSc ${ }^{1, \oplus}$, Wen Ting Yu PharmD MSc ${ }^{1}$, Niina Kleiber MD MSc ${ }^{1,2}$, \\ Stéphanie Tremblay BPharm MSc ${ }^{1}$, Marie-Élaine Métras PharmD MSc ${ }^{1}$, \\ Denis Lebel BPharm MSc FCSHP ${ }^{1}$, Jean-François Bussières BPharm MSc MBA FCSHP ${ }^{1,3}$ \\ ${ }^{1}$ Pharmacy Department and Pharmacy Practice Research Unit, CHU Sainte-Justine, Montreal, Quebec; ${ }^{2}$ Department \\ of General Paediatrics and Clinical Pharmacology Unit, CHU Sainte-Justine, Montreal, Quebec; ${ }^{3}$ Faculté de pharmacie, \\ Université de Montréal, Montreal, Quebec
}

Correspondence: Jean-François Bussières, Pharmacy department, CHU Sainte-Justine, 3175 chemin de la Côte Sainte-Catherine, Montreal, Quebec H3T 1C5. Telephone +1-(514)-345-4931 ext: 5053, fax +1-(514)-345-4820, e-mail jf.bussieres@ssss.gouv.qc.ca

\begin{abstract}
Objective: To describe the problems faced by young patients and their parents when obtaining and using compounded drugs.

Methods: This prospective observational descriptive study included patients 0 to 21 years of age who were discharged from a mother-child tertiary hospital with a prescription containing at least one compounded drug between February 2016 and July 2016. Families were called 7 to 10 business days after discharge to complete a telephone follow-up questionnaire. Retail pharmacies were contacted to obtain additional information in order to compare the dispensed compounded drug with the prescription and published master formulas.
\end{abstract}

Results: The parents of 71 patients with a median age of 6.9 months were surveyed regarding 99 compounded drugs corresponding to 34 different oral formulations. Out of 314 issues identified, 252 were considered as problems: 9 involved major and 243 minor problems with real or potential consequences.

Conclusion: This study identified a significant number of compounding-related problems. It suggests that current practice standards are insufficient and action should be taken to improve the use and the dispensation of compounded drugs to ensure patients' safety.

Keywords: Compounding; Pharmacy; Pediatric; Drug-related problems.

Treating children with medication requires accurate drug dosing for a broad weight range. However, many commonly used drugs are not available in formulations suitable for children (1). Therefore, pharmacists must adapt available adult formulations, often by creating compounded liquid formulation with crushed tablets and excipients. Compared to commercially available drugs, compounded drugs lack an official product label, adapted dispensing tools, and optimized palatability (2-4). More importantly, compounding implies manipulations associated with an increased risk of error. Under- or overdosing of the active substance has been associated with treatment failure and intoxications, leading to hospitalization and even death (5-13). Other problems reported are treatment interruption, misleading instructions, and problems related to the reimbursement of the drug by the patient's insurance $(7,8,14)$.

These safety issues motivated health authorities worldwide to restrict the use of compounded drugs to situations of therapeutic need or lack of product availability (2). Both situations are common in paediatrics and therefore children are vulnerable to compounding-related issues. These problems have 
mostly been described in case reports or case series and mainly focused on the content of the compounded drug. Systematic studies characterizing all problems associated to their preparation and use are lacking. Therefore, the aim of the present study is to characterize the problems experienced at every step of compounded drug preparation, obtainment and use.

\section{METHODS}

\section{Compounding in Quebec and standard procedure in our tertiary care centre}

In many countries, strict standards have been developed to reduce risks associated with compounding (e.g., United States Pharmacopeia) (15,16). In Canada, commercially available products fall under the responsibility of Health Canada but compounded drugs are regulated by provincial regulatory authorities (2). In the province of Quebec, in Canada, the Quebec Order of Pharmacists or Ordre des Pharmaciens du Québec (OPQ) published standards of practice for drug compounding (17-19).

Compounded drugs are classified into three categories according to the standards of the OPQ (OPQ categories). Category 1, referred to as 'simple preparations', includes all simple preparations made without hazardous drugs or substances. Category 2 includes preparations requiring specific techniques and is referred to as 'complex preparations'. Category 3 includes all preparations made with hazardous drugs or substances as classified by the National Institute for Occupational Safety and Health (NIOSH) and is referred to as 'NIOSH preparations' (17). In Quebec, retail pharmacies can prepare the compounded drug or obtain it from specialized compounding pharmacies.

At discharge from CHU Sainte-Justine, pharmacists provide compounded drugs for a few days with instructions of use to palliate potential compounding-associated issues. They may also send published master formulas to the retail pharmacies. This individualized care was maintained throughout the study. Patients discharged during the night or the weekend might not always benefit from those services.

\section{Study design and population}

We conducted a prospective observational study in a mother-child tertiary university hospital from February 2016 to July 2016. All consecutively admitted patients aged 21 years or younger discharged with a prescription containing at least one compounded drug were eligible. Only new prescriptions of compounded drugs delivered by a retail pharmacy were included. Families with insufficient understanding of English or French to complete the survey were excluded. The CHU SainteJustine Research Ethics Board approved the study and all participating families provided written informed consent.

\section{Study procedures}

Toward the end of their hospital stay, eligible patients were approached by the clinical pharmacist. A pharmacy resident from the research team obtained the parents' informed consent and collected demographic and socioeconomic data. Within 7 to 10 business days after discharge, enrolled families were contacted to complete a telephone follow-up questionnaire. The follow-up date was postponed if needed to allow parents to obtain and use the compounded drug. The retail pharmacy was contacted thereafter. Issues experienced at every step of drug preparation, obtainment and use, detailed in Supplementary Table 1, were explored by interviewing the parents and by contacting the pharmacy: reception of the prescription by the dispensing pharmacy, data entry and label creation, prescription validation, compounding and packaging, dispensation, and use.

Every reported inconvenience or concern was considered as an issue. Only issues with real or potential consequences were defined as problems and further classified as having minor (deprived of major safety concern) or major consequences (with major safety concern). Classification of severity is provided in Supplementary Table 2. This classification process was done independently by two research team members who discussed discrepancies to find a consensus. In case of remaining disagreement, a third research team member was involved. When an incidental finding carrying a risk to the patient was discovered during the study, retail pharmacists were informed and measures were taken to ensure patients' safety.

The discharge prescription was compared with published master formulas (the hospital's current master formulas or master formulas from Vigilance Santé (20), a drug database). A discrepancy was defined as any difference between the compounded drug and the physician's prescription and/or available published compounding master formulas. Discrepancies that could affect the participant were considered as issues by the research team (Supplementary Table 3).

\section{Study outcomes}

The primary outcomes were to identify the barriers to obtain the compounded drug and to describe the problems at every step of compounded drug preparation, obtainment, and use reported by parents.

Secondary outcomes were to describe the problems reported by the research team and to identify discrepancies and their related problems between the compounded drug dispensed by the retail pharmacy, and the discharge prescription and available published master formulas used for compounding.

\section{Statistical analysis}

Considering the time frame of this study, a sample size of 100 compounded drugs was deemed adequate to meet our objective. Problems were reported using descriptive statistics. 
Normally distributed data were described using mean and standard deviation (SD) while non-normally distributed data were described using median and interquartile range (IQR). Categorical variables were described using percentage. Analyses were performed using Microsoft Access Database version 2010 and SPSS version 24.

\section{RESULTS}

\section{Participant characteristics}

Among 130 eligible patients, 43 could not be approached before discharge, because clinical pharmacists were not reached in time by the pharmacy resident or because the patient quickly left the hospital. Out of 87 approached patients, 85 gave informed consent. Twelve were excluded according to study criteria, mostly because the compounded drug was ceased before discharge. Of the remaining 73 patients, 71 completed the follow-up questionnaire ( $97 \%$ response rate) for a total of 99 compounded drugs (Figure 1).

Median age was 6.9 months (IQR 13.3), 67\% were Caucasian and $69 \%$ privately insured (Table 1). Parents' highest degree of education was high school in $62 \%$, and $41 \%$ of parents had an annual household income between $\$ 50,000$ and $\$ 99,999$.

\section{Compounded drug characteristics}

Thirty-four different oral compounded drugs were prescribed and all were oral suspensions or solutions. The most commonly prescribed were amlodipine (11\%), levetiracetam (10\%), and tacrolimus (8\%). Sixty-two out of 99 (63\%) compounded drugs were prepared by the dispensing pharmacy (Table 1 ).

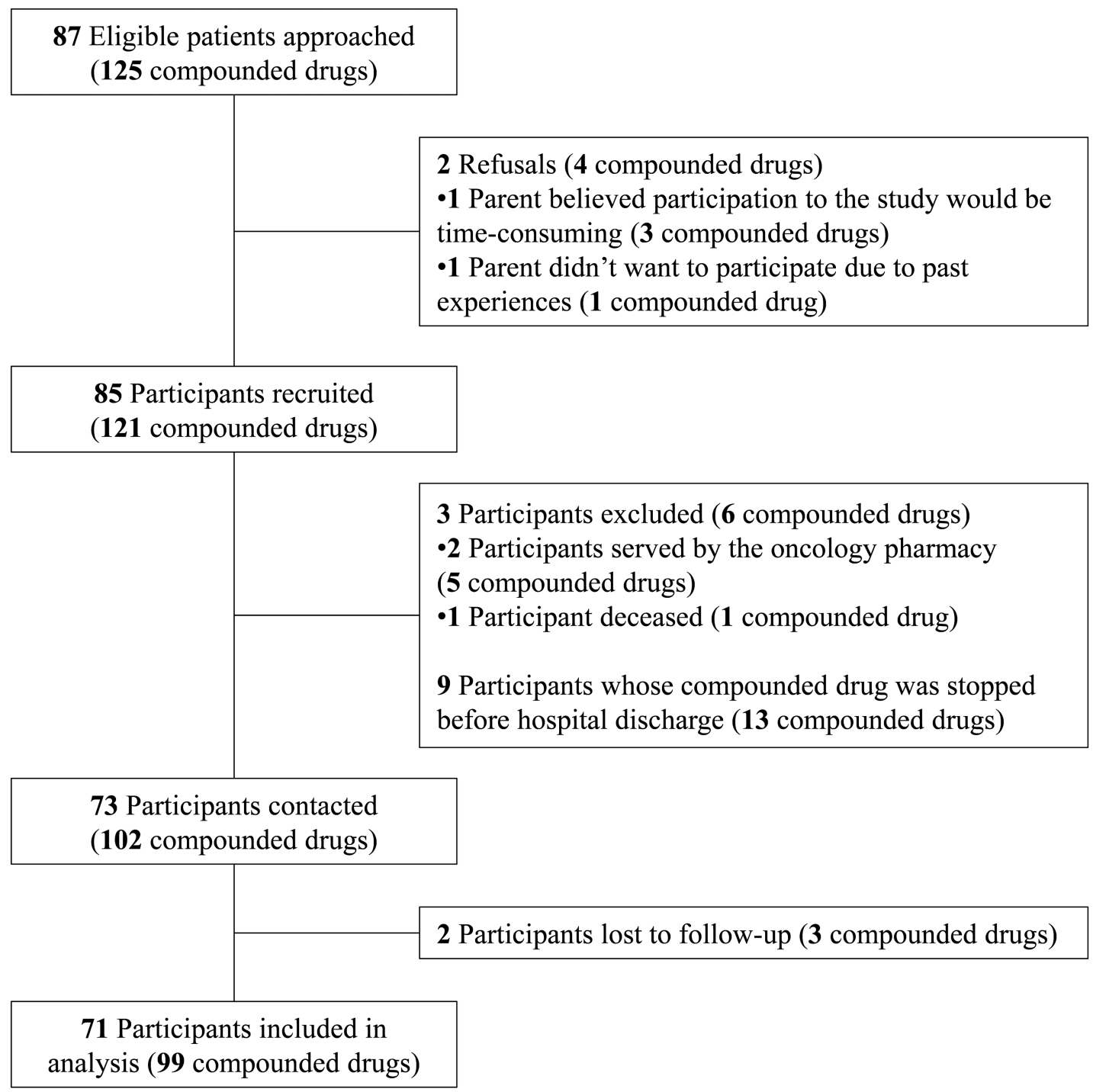

aParticipant: patients and their families

Figure 1. Flow chart and follow-up of participants ${ }^{\mathrm{a}}$ and their compounded drugs. 
Table 1. Participant ${ }^{\mathrm{a}}$ and compounded drug characteristics

\begin{tabular}{|c|c|}
\hline Characteristic & No. \\
\hline Participant ${ }^{\mathrm{a}}$ characteristics & $\mathrm{n}=73$ \\
\hline Age at discharge from hospital & $\mathrm{b}$ \\
\hline Median (IQR), months & $6.9(13)$ \\
\hline Maximum, years & 11 \\
\hline Sex, male, n (\%) & $46(63)$ \\
\hline Ethnicity, n (\%) & $\mathrm{b}$ \\
\hline White & $49(67)$ \\
\hline Arabic & $10(14)$ \\
\hline Black & $5(7)$ \\
\hline Aboriginal peoples & $2(3)$ \\
\hline Other & $7(10)$ \\
\hline $\begin{array}{l}\text { Discharged from hospital during working days, } \\
\mathrm{n}(\%)\end{array}$ & $61(84)$ \\
\hline Drug insurance plan, n (\%) & $\mathrm{b}$ \\
\hline Private & $50(69)$ \\
\hline Public & $23(32)$ \\
\hline Parental highest level of education, $\mathrm{n}(\%)$ & $\mathrm{b}$ \\
\hline High school $^{c}$ & $45(62)$ \\
\hline College/University & $24(33)$ \\
\hline Not reported/declared & $4(6)$ \\
\hline Annual household income, $\mathrm{n}(\%)$ & $\mathrm{b}$ \\
\hline$\$ 10,000-\$ 49,999$ & $20(27)$ \\
\hline$\$ 50,000-\$ 99,999$ & $30(41)$ \\
\hline More than $\$ 100,000$ & $12(16)$ \\
\hline Not reported/declared & $11(15)$ \\
\hline Number of compounded drugs per participant & $\mathrm{b}$ \\
\hline Median (IQR), n & $1.0(1)$ \\
\hline Maximum, $\mathrm{n}$ & 4 \\
\hline Compounded drug characteristics & $\mathrm{n}=99$ \\
\hline Place of preparation, $n$ & $\mathrm{~b}$ \\
\hline Dispensing pharmacy ${ }^{d}$ & $62(63)$ \\
\hline Specialized compounding pharmacy & $18(18)$ \\
\hline Unknown & $19(19)$ \\
\hline Compounded drug dispensing, $n$ & $\mathrm{~b}$ \\
\hline Parent returned to the pharmacy to obtain it & $88(89)$ \\
\hline $\begin{array}{l}\text { Compounded drug delivered to the participant's } \\
\text { home }\end{array}$ & $8(8)$ \\
\hline Parent waited at the pharmacy to obtain it & $3(3)$ \\
\hline
\end{tabular}

$I Q R$ Interquartile range.

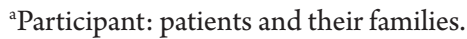

'Empty cells because corresponding cells are categories and therefore have no results.

'Includes elementary school, high school, diploma of vocational studies and CEGEP education.

${ }^{\mathrm{d} D i s p e n s i n g ~ p h a r m a c y: ~ d i s p e n s e s ~ t h e ~ c o m p o u n d e d ~ d r u g, ~ w h e t h e r ~}$ it compounds it or not.
Supplementary Table 4 presents the characteristics of the compounded drugs. Seventy-five compounded drugs (76\%) required simple preparation, 5 (5\%) implied complex preparation, and 19 (19\%) were NIOSH preparations.

According to the parents, doses of the compounded drugs were provided at hospital discharge for 90 compounded drugs (median 7 days of treatment; IQR 4) and hospital pharmacists contacted the retail pharmacists before discharge for 69 compounded drugs.

Retail pharmacists used the same ingredients as in the current hospital master formulas for 69 (70\%) compounded drugs. Data were missing for 10 compounded drugs, and ingredients were different for 20 compounded drugs. The formulation's concentration dispensed by the retail pharmacy was different from the hospital master formulas' concentration for five compounded drugs, but no parent reported giving the wrong dose in volume.

\section{Outcomes}

A total of 314 issues were identified among which 252 involved real or potential consequences and were therefore considered as problems. One hundred and thirteen problems were reported by parents and 139 by the research team. Nine involved major and 243 minor consequences (real or potential).

\section{Primary outcome}

Table 2 presents the 113 problems reported by parents and classified according to their severity. Six problems had major consequences (real or potential): one parent gave the wrong dose of two different drugs during a week due to a misunderstanding of the administration instructions. Four patients experienced delay in drug delivery by the pharmacy and consequently, one patient missed two doses and three returned to the hospital pharmacy to get additional doses. One hundred and seven problems had minor consequences (real or potential). On nine labels, the names of the drug and of the ingredients were diffcult to read. Twelve compounding problems were due to delays or miscommunications between parents and retail pharmacies. Among 29 dispensing issues, 21 (72\%) were related to insurance or cost issues.

Supplementary Table 5 describes the barriers to obtain the drug. Eight families had to visit more than one pharmacy mainly because of the lack of appropriate equipment. The median delay in obtaining the compounded drug was 24 hours (IQR 66.0), and the maximal delay was 12 days. The reported reasons for the delay were: the time-consuming preparation process and the delay for the dispensing pharmacy to receive the missing ingredients or the drug prepared by a compounding pharmacy. For 13 compounded drugs, retail pharmacies asked parents to 
Table 2. Issues reported by parents per compounded drug and consequence severity

\begin{tabular}{|c|c|c|c|c|}
\hline Issue & \multirow{2}{*}{$\frac{\text { No. }(\%)}{a}$} & \multirow{2}{*}{$\overline{\text { a }}$} & \multirow{2}{*}{$\frac{\text { Consequences }(\mathrm{n}=147)}{\text { Minor }}$} & \multirow{2}{*}{$\overline{\text { a }}$} \\
\hline a & & & & \\
\hline 1. Reception of the prescription by the dispensing ${ }^{\mathrm{b}}$ pharmacy & $10(7)$ & 1 & 9 & \\
\hline 2. Data entry and label creation & $18(12)$ & 2 & 16 & \\
\hline 3. Prescription validation & $1(1)$ & & 1 & \\
\hline 4. Compounding and packaging & $18(12)$ & & 16 & 2 \\
\hline 5. Dispensing & $29(20)$ & 3 & 25 & 1 \\
\hline 6. Drug use & $63(43)$ & 28 & 32 & 3 \\
\hline 6.1. Container & $5(8)$ & 5 & & \\
\hline 6.2. Measuring & $38(60)$ & 15 & 21 & 2 \\
\hline 6.3. Administration to the child & $17(27)$ & 8 & 8 & 1 \\
\hline 6.4. Storage & $3(5)$ & & 3 & \\
\hline 7. Other & $8(5)$ & & 8 & \\
\hline Total & 147 & 34 & 107 & 6 \\
\hline Total of problems & & & 113 & a \\
\hline
\end{tabular}

${ }^{a}$ Empty cell because it has to be merged.

${ }^{b}$ Dispensing pharmacy: dispenses the compounded drug, whether it compounds it or not.

notify them in advance to prepare the compounded drug. The median advance notice requirement was 1.5 day (IQR 2 ), with a minimum of 2 hours and a maximum of 5 days.

\section{Secondary outcomes}

Table 3 presents the 73 problems identified by the research team when comparing the compounded drugs with the original prescription and published master formulas among which three had major consequences (real or potential). One label lacked the name of the active ingredient and the excipients. Two compounding errors led to an $11 \%$ higher prednisone dose and a $40 \%$ higher sildenafil dose. The latter was due to confusion between sildenafil free base and salt forms, and necessitated a medical follow-up. Seventy problems involved minor (real or potential) consequences. Minor consequences related to ingredients were substitution for another excipient, absence or use of additional excipients compared with published master formulas leading to unknown stability. The most frequent minor consequence was related to labels lacking the instruction to shake adequately leading to potential uneven active substance concentration.

Sixty-six problems were identified by the research team at the interview and all involved minor consequences (Supplementary Table 6). The most frequent issue was related to dispensing (46\%) and was mainly due to the measuring tool not being provided nor explained.

\section{DISCUSSION}

To our knowledge, this is the first study systematically describing problems related to every step of compounded drug preparation, obtainment and use in paediatrics. Among 99 compounded drugs dispensed to 71 patients, a mean of 3.5 problems per patient were identified and $4 \%$ involved major consequences (real or potential).

In our study, almost every patient experienced problems, which is higher than the rate of issues reported by McElhiney et al. of 15 to $58 \%$, in a randomized controlled trial including 25 patients (7). This discrepancy may be explained by the fact that only a few steps of drug preparation and obtainment were considered whereas our study evaluated all steps of drug preparation, obtainment, and use. Our study, with its larger sample size, reports a wider range of problems which involves different stakeholders. Revealed problems were sometimes attributable to retail pharmacies' software not being adapted to data entry of compounded drugs, problems with insurance coverage, unreadable or incomplete labels, imprecise master formulas, missing instructions for use, or absence of tool dispensation.

Delay to obtain the drug was considerable with a median duration of 24 hours (IQR 66.0). Despite this delay, only one participant missed doses. This low number of missed doses is probably due to the hospital pharmacist's practice of dispensing a few days of compounded drug at discharge. In the aforementioned study by McElhiney et al., the impact of the hospital pharmacist's interventions was shown (7). The intervention group received information on compounded drugs and was given the possibility to obtain some doses at discharge while the control group was discharged without individualized care. In the intervention group, $15 \%$ of patients experienced issues compared to $58 \%$ in the control group. The present study shows that despite individualized care by hospital pharmacists, an important number of problems still occur, suggesting that an 
Table 3. Discrepancies and associated issues identified by the research team and consequence severity and associated problems

\begin{tabular}{|c|c|c|c|c|c|}
\hline Variable & $\begin{array}{l}\text { Discrepancies No. } \\
\text { (\% of total) }\end{array}$ & $\begin{array}{l}\text { Issues No. (\% of } \\
\text { discrepancies) }\end{array}$ & a & $\begin{array}{l}\text { Consequences } \\
(\mathrm{n}=75)\end{array}$ & a \\
\hline a & a & a & None & Minor & Major \\
\hline $\begin{array}{l}\text { Name/formulation and concentration } \\
\qquad(\mathrm{n}=98)\end{array}$ & $15(8)$ & $4(27)$ & & 3 & 1 \\
\hline Ingredients and quantities $(\mathrm{n}=87)$ & $31(16)$ & $16(52)$ & & 15 & 1 \\
\hline Dose $(n=99)$ & $5(3)$ & $4(80)$ & & 2 & 2 \\
\hline $\begin{array}{l}\text { Drug regimen and administration } \\
\text { route }(\mathrm{n}=99)\end{array}$ & $17(9)$ & $4(24)$ & 1 & 3 & \\
\hline $\begin{array}{l}\text { Treatment duration and number of } \\
\text { refills }(\mathrm{n}=99)\end{array}$ & $36(19)$ & $17(47)$ & & 17 & \\
\hline Beyond-use date $(n=98)$ & $26(14)$ & $7(27)$ & & 7 & \\
\hline Storage $(n=98)$ & $4(2)$ & $3(75)$ & & 3 & \\
\hline Conditioning $(\mathrm{n}=98)$ & $3(2)$ & $1(33)$ & & 1 & \\
\hline Use information/instructions $(\mathrm{n}=98)$ & $37(20)$ & $18(49)$ & & 18 & \\
\hline Appearance $(n=94)$ & $15(8)$ & $1(7) b$ & & 1 & \\
\hline Total & 198 & $73^{b, c, d}$ & $0^{\mathrm{d}}$ & $70^{\mathrm{b}, \mathrm{c}}$ & $3^{d}$ \\
\hline Total of problems & & & & 73 & a \\
\hline
\end{tabular}

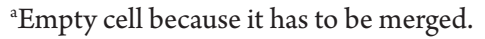

${ }^{\mathrm{b}}$ One appearance problem not counted because it was already reported by parent.

'One drug not dispensed as a compounded drug, considered as a problem because of no data on stability.

${ }^{\mathrm{d}}$ One dose problem caused a drug regimen problem and one ingredient quantity problem caused a dose problem (they have been counted as only one problem each).

effort should be directed toward improving the process of drug preparation, obtainment and use.

In our study, discrepancies between the compounded drug ingredients and the hospital master formula's ingredients were found for $20 \%$ of compounded drugs. Similar results have been described by Hurtado et al. in a retrospective study conducted in the Texas Children's Hospital on 40 compounded drugs (9). Fifty per cent of the retail pharmacies used the same master formula as the hospital's, $30 \%$ could not disclose the master formula used, and $20 \%$ used an unpublished master formula.

This study has several strengths. The sample size was larger than in most similar studies. An independent adjudication process ensures reliability of the classification of the problems' severity. The semistructured questionnaire allowed parents to report problems or inconveniences that may not have been suspected by the research team.

This study also has limitations. Information obtained by parents is subjective and prone to memory bias. This is an uncontrolled single-centre study and some of the problems may not be specific to compounding. Despite individualized pharmaceutical care, problems were very frequent in our study. Many hospitals do not benefit from similar individualized care of a pharmacist suggesting that the number and severity of problems may be higher in other settings. Therefore, it would be beneficial to replicate the study in other care units where pharmacists are not involved. This study was conducted in Quebec, Canada, which could make some issues less generalizable to other provinces and countries.

This study sheds light on the problems related to compounding and calls for solutions. Labelling issues should motivate the implementation of software adapted for drug compounding with standardized label content. Compounding master formulas should be standardized using the best quality data and should be made widely available to pharmacists (e.g., via a website). The price of compounded drugs and the reimbursement process should be defined. Problems with the use of compounded drugs could be prevented by providing standardized written information about the utilization and storage of the compounded drug, and use of the most precise measuring tools. Finally, more incentives are needed to encourage pharmaceutical companies to develop commercial or off-patent drugs adapted to the paediatric population.

\section{CONCLUSION}

This study is the first to show that compounding-related problems are frequent and can arise at every step of drug preparation, obtainment and use. The risk for patients' safety is significant despite the effort and the individualized care of hospital pharmacists in our health care centre. It suggests that such practice 
standards are insufficient and suboptimal to ensure adequate patients' safety. To limit the risk for patients, health authorities around the world should continue to develop incentives to motivate the development of commercial products adapted to children's unique needs. When compounding is required, standardized master formulas, based on the best published data, should be used to reduce risks and confusion.

\section{SUPPLEMENTARY DATA}

Supplementary data are available at Paediatrics \& Child Health Online.

\section{Acknowledgements}

We thank the families who participated in the study, as well as all the pharmacists at CHU Sainte-Justine for their assistance with the study. We also thank Mr. Jean-Marc Forest, B. Pharm., M. Sc., from CHU Sainte-Justine, for answering drug-compounding-related questions and for content review.

Institution where the work originated: CHU Sainte-Justine.

Ethics board: CHU Sainte-Justine Research Ethics Board.

Funding Details: There is no funding to report for this submission.

Potential Conflicts of Interest: All authors: No reported conflicts of interest. All authors have submitted the ICMJE Form for Disclosure of Potential Conflicts of Interest. Conflicts that the editors consider relevant to the content of the manuscript have been disclosed.

\section{References}

1. Giacoia GP, Taylor-Zapata P, Zajicek A. Drug studies in newborns: A therapeutic imperative. Clin Perinatol. 2012;39(1):11-23.

2. Santé Canada. Politique sur la fabrication et la préparation en pharmacie de produits pharmaceutiques au Canada. Ottawa, Canada. 2009 (updated February 6, 2009; cited October 12, 2015). Available from: http://www.hc-sc.gc.ca/dhp-mps/ alt_formats/hpfb-dgpsa/pdf/compli-conform/pol_0051-fra.pdf. Accessed August $3, \overline{2} 017$.

3. National Association of Pharmacy Regulatory Authorities. Health Canada "Manufacturing and Compounding Drugs Products in Canada: A Policy Framework" Guidelines for P.E.I. Community and Hospital Pharmacists. 2001 (cited October 12, 2015); Octobre:[6 p.]. Available from: http://napra.ca/content_files/files/pei/ standardsguidelines/manufactvscmpd.pdf. Accessed August 3, $201 \overline{7}$.
4. Ordre des pharmaciens du Québec. Guide des soins et services pharmaceutiques: Rôle 6 Gérer les médicaments (cited October 12, 2015). Available from: http:// guide.opq.org/6_Role_02.html\#A122. Accessed August 3, 2017.

5. Thiessen JJ. A Review of the Oncology Under-Dosing Incident Toronto. 2013 (cited October 12, 2015). Available from: http://www.wrh.on.ca/Site_Published/wrh_ internet/Document.aspx?Body.Id=51971. Accessed August 3, 2017.

6. Seifert SA, Jacobitz K. Pharmacy prescription dispensing errors reported to a regional poison control center. J Toxicol Clin Toxicol 2002;40(7):919-23.

7. McElhiney LF Pharmd Rph. Educating the caregiver and community pharmacist to facilitate provision of consistent compounded medications from the inpatient to ambulatory settings. Int J Pharm Compd 2003;7(5):394-8.

8. Institute for Safe Medication Practices. Oral Liquid Medications May Be More Vulnerable to Errors than Previously Recognized. 2000 (cited October 15, 2015). Available from: https://www.ismp.org/newsletters/acutecare/articles/20000628_2.asp. Accessed August 3, 2017.

9. Hurtado J Rph. Pediatric oral formulations: A continual challenge. Int J Pharm Compd 2007;11(1):17-9.

10. Suchard JR, Graeme KA. Pediatric clonidine poisoning as a result of pharmacy compounding error. Pediatr Emerg Care 2002;18(4):295-6.

11. Romano MJ, Dinh A. A 1000 -fold overdose of clonidine caused by a compounding error in a 5-year-old child with attention-deficit/hyperactivity disorder. Pediatrics 2001;108(2):471-2.

12. Centers for Disease Control and Prevention. Deaths from Intravenous Colchicine Resulting from a Compounding Pharmacy Error--Oregon and Washington, 2007. 2007 (updated October 12, 2007; cited October 12, 2015);56(40):1050-2. Available from: https://www.cdc.gov/mmwr/preview/mmwrhtml/mm5640a3. htm. Accessed August 3, 2017.

13. Grissinger M. Another tragic parenteral nutrition compounding error. P T 2014;39(12):810-22.

14. Régie de l'assurance maladie du Québec. Manuel des pharmaciens. 2014 (cited October 12, 2015): [219 p.]. Available from: http://www.ramq.gouv.qc.ca/ SiteCollectionDocuments/professionnels/manuels/260-pharmaciens/000_complet_pharm.pdf. Accessed August 3, 2017.

15. United States Pharmacopeial Convention. <795> Pharmaceutical Compounding - Nonsterile Preparations: USP; 2011 (cited October 12, 2015); 2nd ed. Available from: http://www.usp.org/sites/default/files/usp pdf/EN/gc795.pdf. Accessed August 3, 2017.

16. United States Pharmacopeial Convention. <797> Pharmaceutical Compounding Sterile Preparations. USP Compounding Compendium. 2015. 2nd ed.

17. Ordre des pharmaciens du Québec. Préparations magistrales non stériles en pharmacie: Norme 2012.01. Québec, Canada 2012 (cited October 12, 2015): [84 p.]. Available from: http://www.opq.org/cms/Media/1088_38_fr-CA_0_ Norme_2012_01_magistrales_non_steriles.pdf. Accessed August 3, 2017.

18. Ordre des pharmaciens du Québec. Préparation de produits stériles non dangereux en pharmacie: Norme 2014.01. Québec, Canada 2014 (cited October 12, 2015): [104 p.]. Available from: http://www.opq.org/cms/Media/1827_38_fr-CA_0_ Norme_2014_01.pdf. Accessed August 3, 2017.

19. Ordre des pharmaciens du Québec. Préparation de produits stériles dangereux en pharmacie: Norme 2014.02. Québec, Canada 2014 (cited October 12, 2015): [116 p.]. Available from: http://www.opq.org/cms/Media/1847_38_fr-CA_0_ Norme_2014_02.pdf. Accessed August 3, 2017.

20. Rx Vigilance. [software]. Vigilance Santé Inc. Repentigny, Canada 2016. 